Int. J. Curr. Res. Med. Sci. (2017). 3(6): 176-182

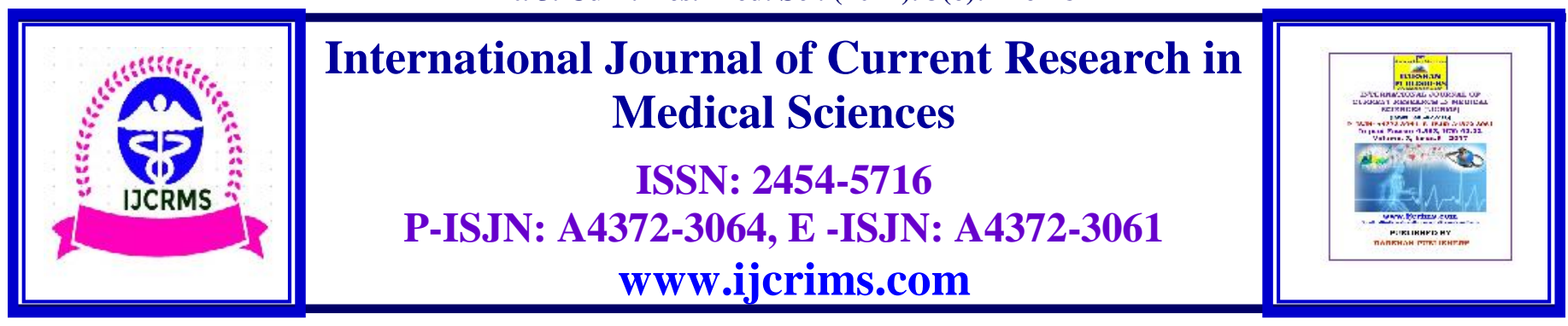

Original Research Article

Volume 3, Issue 6 -2017

DOI: http://dx.doi.org/10.22192/ijcrms.2017.03.06.023

\title{
Inferior Pedicle Reduction Technique With Nipple Repositioning for Huge Gynecomastia
}

\author{
Mostafa Mahmoud Salama. \\ Department of General Surgery, Al-Azhar University Hospitals, \\ Faculty of Medicine, Al-Azhar University, \\ Cairo, Egypt \\ Mohammed Mamdouh Ahmed \\ Department of General Surgery, Al-Azhar University Hospitals, \\ Faculty of Medicine, Al-Azhar University, \\ Cairo, Egypt
}

\begin{abstract}
Background : Gynecomastia (GM) is a common benign problem affecting males. Many surgical techniques have been described. We discuss in this study a technique used for large redundant male breast using deepithelialized inferior pedicle with nipple areola repositioning. Patients and method: The study included 10 patients (with total 20 breasts) with huge gynecomastia treated surgically using inferior pedicle technique. They were operated in $\mathrm{Al} A z h a r$ university hospital between May 2015 and April 2017. All the patients have bilateral GM with age range from 30 to 48. The operation started by deepithelialization of the ellipse and dissection between the inferior glandular pedicle and chest wall removing breast tissue as we need. The superior breast flap was raised with thickness not more than 1$2 \mathrm{~cm}$. A disc of skin and subcutaneous fat then removed at the future nipple-areola site at upper flap. The inferior pedicle pulled up under the upper flap and the nipple areola complex of the lower flap was then repositioned at the new site and sutures using prolene 5/0. Suction drain was used in all patients. Results: The operated 20 breasts ended by good asthetic results and patient satisfaction with only 3 breasts showed wound infection and 2 breasts showed seroma. Conclusion: The inferior pedicle method for the management of Simon grade III gynaecomastia is a satisfactory method for treatment of these severe cases.
\end{abstract}

Keywords: Gynecomastia, inferior pedicle technique, seroma.

\section{Introduction}

Gynaecomastia is a benign disease occuring in men with an incidence of $32 \%-65 \%$ (Yavuz et al., 2006). Gynaecomastia usually results from a hormonal imbalance as may be seen postnatally, during puberty, and in the elderly. Inspite of being mostly idiopathic, pathological causes must be ruled out; these include congenital, chromomal abnormalities (like klinefilter syndrome), endocrine disorders (like cushing disease), neoplasm, and drugs. GM may be unilateral or bilateral, symmetrical or asymmetrical (Bembo and Carlson 2004). Simon et al. suggested a 4- 
grade classification which is: I: Small enlargement without skin excess, IIA: Moderate enlargement without skin excess, IIB: Moderate enlargement with minor skin excess, III: Marked enlargement with excess skin, mimicking female breast (Simon et al., 1973). Diagnosis and treatment may require medical, surgical, and psychological management. Certain cases may be treated by drugs, but this may fail and endocrinologist refer these patients to surgeon (Fischer et al., 2014). The gold standard therapy for GM seems to be surgery however, the choice of an ideal operation is still challenging. The issue of scar containment is of great importance when deciding to operate (Kasielska and Antoszewski 2013). That is why, the option to make a periareolar incision has been developed. This incision can be extended further laterally and medially. The nipple-areola complex is then pulled anteriorly by the assisstant, and the underlying breast tissue is excised either by sharp dissection or liposuction. Afterwards, hemostasis is achieved using electrocautery, the wound is copiously irrigated, and skin edges are reapproximated with a running 3-0 or 4-0 Monocryl subcuticular stitch (Ismail et al., 2006). One technique for treating larger forms of gynecomastia that include redundant skin is presented here. The nipple-areola complex with its blood and nerve supply can be carried on an inferior pedicle after being de-epithelialized, and this will correct areola hypertrophy and ptosis. An upper flap, based superiorly, is then pulled down over the inferior pedicle and redundant excess skin is excised at the infra-mammary fold. The result is a nipple-areola complex with intact neurovascular supply and only periareolar and infra-mammary scars (Andrew et al., 1992).

\section{Patients and Methods}

This study was conducted on 10 patients presented by huge gynecomastia (grade III). They were operated in Al Azhar university hospital between May 2015 and March 2017. All the patients have bilateral GM with age range from 30 to 48 . Every breast is considered an individual case, thus we will coduct the results as 20 cases. Patients with Simon grade I or II bilaterally, severe comorbidity, older than 55 years, chronic liver disease, drug addiction, thyroid disease, previous breast operation and mentally abnormal patients were excluded from the study. All patients were exposed to full history taking specially drug history, liver disease and thyroid problems, general examination and examining the breasts, liver and scrotum specifically. Investigations like liver function tests and hormonal profile were ordered in some patients. A consent explaining the operation and mentioning the risk and complications was taken from all patients. All patients were operated under general anaesthesia, after marking using a line extending from midclavicular line passing by the nipple (breast meridian) and ellipse mark to be deepithelialized and the site of future nipple areola complex (one finger breadth above a point of intersection of breast meridian and inferior border of pectoralis major muscle). Bilateral symmetry was ascertained. The operation started by deepithelialization of the ellipse and dissection between the inferior glandular pedicle and chest wall removing breast tissue as we need. The superior breast flap was raised with thickness not more than 1-2 $\mathrm{cm}$ and breast tissue removed to chest wall. A disc of skin and subcutaneous fat then removed at the future nipple site at upper flap. The inferior pedicle pulled up under the upper flap and the nipple areola complex of the lower flap was then repositioned at the new site and sutures using prolene 5/0. Suction drain was used in all patients. The operation ended with transverse wound at the site of the inframammary fold and sutured using prolene 3/0. Drains were removed around one week and sutures after two weeks. Patients were followed for a minimum of 3 months, with vest recommended for all patient for a period around 1.5 months. All the patients were inquired about the scar and self satisfaction, self confidence and sensation. Any complication was documented. 


\section{Results}

During the study period 10 patients were included with total 20 breasts operated. Age range from 30 to 48 years (mean 36.3). 7 patients were referred for psychological reasons and a for pain and discomfort. 5 patients presented after severe weight loss with redundant skin without excess glandular tissue. The rest of patients have longstanding gynecomastia treated initially medically then neglected until reaching huge stage (duration more than $10 \mathrm{yr}$ ). All cases have symmetrical breasts except 2 cases. 8 patients have U/S assessment of breasts. 2 patient have FNAC for palpable abnormally firm area of one breast and the results are normal . 2 patients have liver function tests for exclusion of liver disease.
3 patients have scrotal U/S for exclusion of testicular atrophy or tumour. One patient with obesity and acne have level of cortisone checked and imaging of adrenal gland but the results are normal. 5 patients were normal weight from 62 to 79,5 patients from 95 to 110 . Very interesting is the time of operation, for each breast individually, from $1.8 \mathrm{hr}$ to $3.9 \mathrm{hr}$. Blood loss ranged from 150 $\mathrm{cc}$ to $320 \mathrm{cc}$ (mean $210 \mathrm{cc}$ ). The weight of excised tissues were documented in all cases and ranged from $120 \mathrm{~g}$ to $200 \mathrm{~g}$ per breast. Complications occurring in the cases were limited to wound infection in 3 breasts, one of them have large wound dehiscence. Seoma after drain removal happened in 2 breasts and managed conservatively.

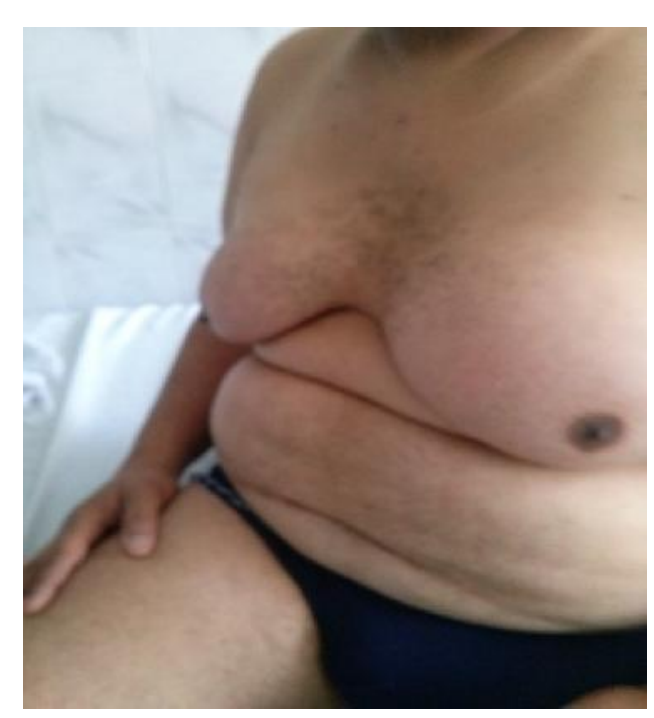

A

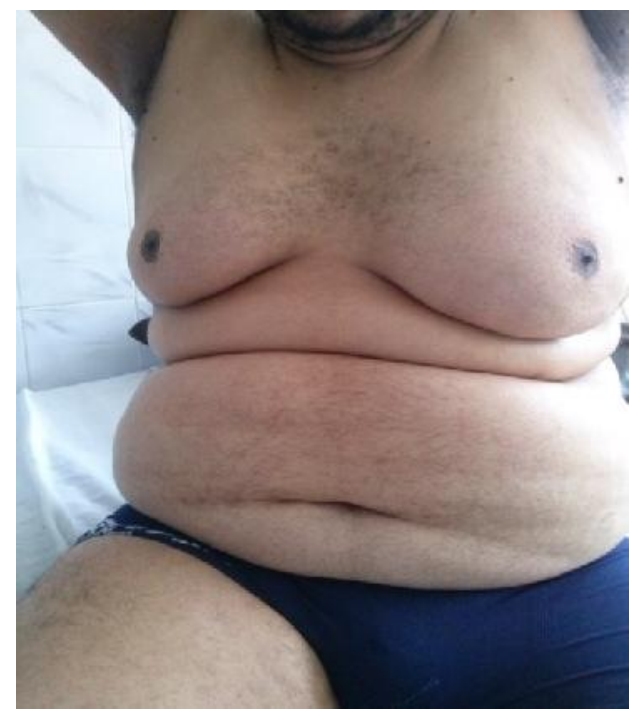

b

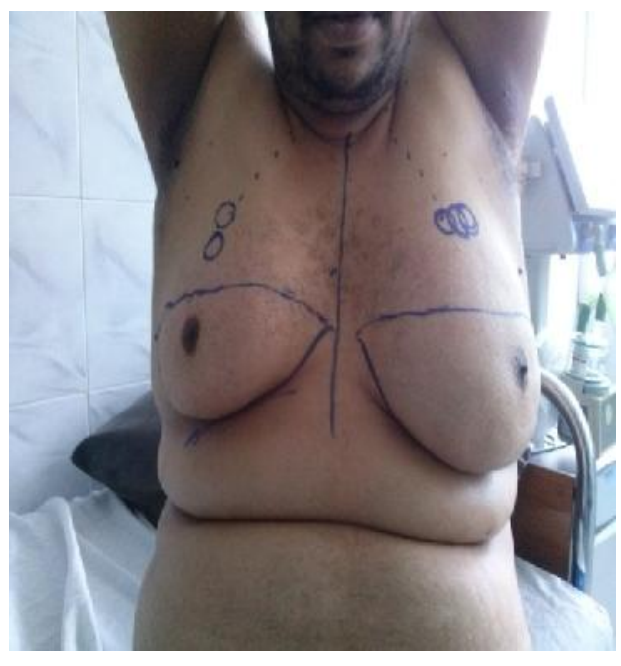

c 
Int. J. Curr. Res. Med. Sci. (2017). 3(6): 176-182

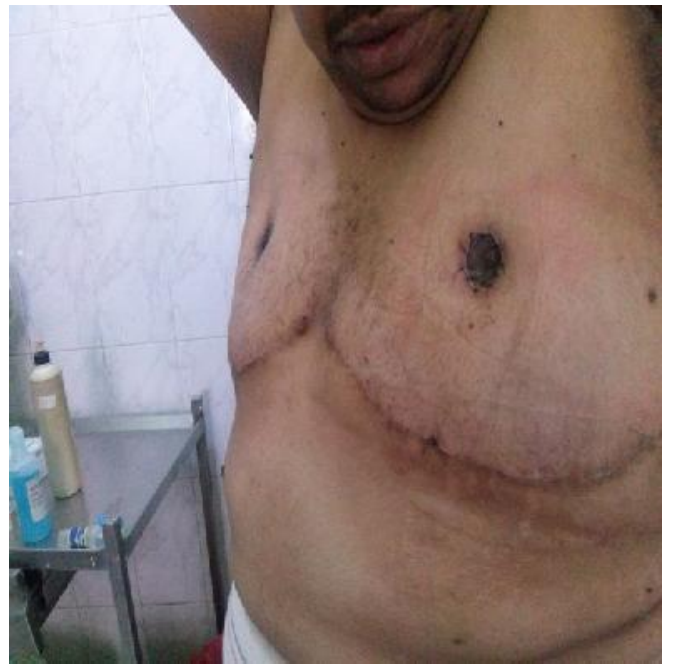

d

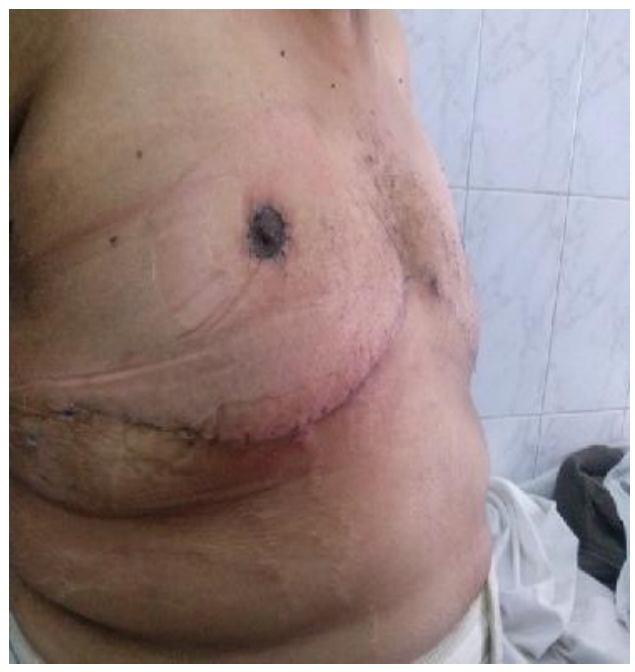

e

Figure (1): preoperative(a,b). operative marking (c) and one month postoperative(e)

Table (1) Age, body weight, duration of symptoms, grade of gynaecomastia.

\begin{tabular}{|l|l|}
\hline Operative details and complications & Results \\
\hline Duration of operation & $1.8-3.9 \mathrm{hr} \mathrm{(mean} \mathrm{2.85)}$ \\
\hline Blood loss & $150-320 \mathrm{cc}$ (mean 235) \\
\hline Excised tissue weight & $120-200 \mathrm{~g} \mathrm{(mean} \mathrm{128)}$ \\
\hline Seroma & 2 breasts (10\%) \\
\hline Wound infection & 3 breasts (15\%) \\
\hline
\end{tabular}

Table (2): Investigations ordered:

\begin{tabular}{|c|c|}
\hline Patients characteristics & Results \\
\hline Age & $30-48 \quad($ mean 36.3$)$ \\
\hline Body weight & $62-110($ mean 79$)$ \\
\hline BMI & $19-39 \quad($ mean 26$)$ \\
\hline $\begin{array}{ll}\text { Complains } & \begin{array}{l}\text { post weight loss } \\
\text { primary }\end{array}\end{array}$ & $\begin{array}{l}5 \text { cases } \\
5 \text { cases }\end{array}$ \\
\hline Duration of symptoms & $2-19$ \\
\hline $\begin{array}{r}\text { Side involved unilateral } \\
\text { Bilateral }\end{array}$ & \\
\hline $\begin{array}{ll}\text { Symmetry } & \text { Symmetrical } \\
& \text { Asymmetrical }\end{array}$ & $\begin{array}{l}8 \text { cases } \\
2 \text { cases }\end{array}$ \\
\hline $\begin{array}{ll}\text { Grade } & \text { Simon G III } \\
& \text { Simon G IIB }\end{array}$ & $\begin{array}{l}18 \text { breasts } \\
2 \text { breasts in } 2 \text { different patients } \\
\text { (asymmetrical) }\end{array}$ \\
\hline
\end{tabular}


Table(3):Operative details and complications.

\begin{tabular}{|l|l|}
\hline Blood tests and imaging & Number of patients \\
\hline Liver function test & $2(20 \%)$ \\
\hline Breast U/S & $8(80 \%)$ \\
\hline FNAC & $2(20 \%)$ \\
\hline Adrenal CT scan & $1(10 \%)$ \\
\hline Scrotal U/S & $3(30 \%)$ \\
\hline Serum hormonal assay & $1(10 \%)$ \\
\hline
\end{tabular}

\section{Discussion}

There are many surgical operations and management protocols for correcting GM in the literature (Handschin et al., 2008). They encompass Simon, Hoffman, and Kahn's simple mastectomy (Simon et al., 1973) and Wray, Hoopes, and Davis' en bloc excision of skin and subcutaneous tissues at the inframammary fold (Wray et al., 1974). While Webster's intraareolar incision is placed inside the inferior border of the nipple-areola complex, the periareolar incision is made along the inferior margin of the areola. Extending the wound bilaterally can be added to both Webster's and the periareolar incisions to gain additional exposure, but the result may be conspicuous scars (Abd El Naser, 2010), (Webster et al., 1946). The disease of severe gynaecomastia with redundant skin, can be treated by many techniques described in literature. Many authors suggested circumareolar skin excision by deepithelialized a concentric circle of periareolar skin and then breast tissue can be removed through the infraareolar incision (Sarrabayrouse et al., 2006). Free nipple graft technique has been also described for stage III gynaecomastia (Mohamad, 2007). Those who prefer this technique urgue this to easy, simple technique and the resultant flat chest rather than the cone like breast shape produced by other techniques. The main disadvantage of this procedure is the long transverse scar. Another disadvantage is the loss or decreased sensation in nipple graft but, fortunately it is not a major problem in the male who only need to remove the embarassing redundant protuberant female-like breast (Mohamad, 2007). Great enthusiasm has greated the introduction of suction assisted lipectomy to gynecomastia surgery because the technique is easy and does not impair areolar vascularity or sensation, and because the postoperative scars are excellent (Stark et al., 1992). It allows fast, efficient and controlled tissue excision, helping to achieve good results. It is established for lipomatous pseudo-gynecomastia, but its value for treating true glandular breast enlargement in male is controversial (Stark et al., 1992). Concentric mastopexy can be also added to liposuction (Sarrabayrouse et al., 2006). In our study, we aimed at treating these male patients complaining of severe gynecomastia by using the technique of inferior dermoglandular pedicle, to excise the excess skin and breast tissue and reposition NAC at normal position. The most attracting value of this, is to obtain well vascularized NAC with intact sensation. The disadvantage of long inferior transverse scar is not of great matter by most patients who have female like breasts. No surgeon can deny the drawback of the long duration of the operation mainly due to deepithelialization of the pedicle necessitating two surgeon working, one for each breast, at the same time. This study included 10 patients with severe gynecomastia. All of them have bilateral enlargement presented mainly due to psychological affection. Their age range from 30-48 yr with no other major health problem, which could prevent them from thinking of this minor problem. All patients were satisfied well with the results because the complications were mild and managed conservatively (3 cases of wound infection and 2 cases of seroma). Only one patient had wound dehiscence. The long duration of the operation with some blood loss are the causes of the postoperative weakness for some days in most patients, and also make the choice of this operation questionable in high risk patients. 
The issues of areolar stretching and ptosis are an additional concern in this patient population. The areola's diameter is greatly exaggerated because of "expansion," necessitating reduction. Some authors have suggested $20-25 \mathrm{~mm}$ as an average areola size (Freiberg ,1987). The diameter of the areola is determined by the surgeon, who uses the breast and chest wall proportions as a guide. Superior and medial translocation of the nippleareola complex is vital in ensuring a natural and masculine appearance. Use of the breast meridian and inferolateral border of pectoralis major are used widely by surgeon for adjusting nipple position. The attention to breast mound-areola proportion greatly enhances the final cosmetic result (Freiberg, 1987).

\section{Conclusion}

The inferior pedicle with transverse scar technique for the management of Simon grade 3 gynaecomastia is a simple easy, practical, satisfactory method with nearly no learning curve. When used for treatment of these severe cases, patients will express their great satisfaction and good nipple sensation.

\section{References}

1- Strak B., Grandel S. and Spilker G.: Tissue suction of the male and female breast. Aesth. Plast. Surg., 16: 317-324, 1992.

2- Freiberg A: Apple-coring technique for severe gynecomastia. Can J Surg 30"57, 1987

3- Handschin AE, Bietry D, Hüsler R, Banic A, Constantinescu M. Surgical management of gynecomastia--a 10-year analysis. World J Surg. 2008;32(1):38-44.

4- Sarrabayrouse M., Loustau H., Mayer H.F.: Versatility of the 360 periareolar approach for the treatment of mammary pathology. Aesth. Plast. Surg., 30: 9-14, 2006.

5- Abd El naser El Nagar, (2010): Circumareolar Inferior Pedicle Mammaplasty for Treatment of Gynecomastia with Breast Ptosis, Med. J. Cairo Univ., Vol. 78, No. 2, September 231240, 2010.

6- Mohammed Abdel Mageed, M.D. Surgical Treatment for Moderate and Large-Sized
Gynaecomastia, Egypt, J. Plast. Reconstr. Surg., Vol. 31, No. 1, January: 45-55, 2007.

7- Simon BE, Hoffman S, Kahn S: Classification and surgical correction of gynecomastia. Plast Reconstr Surg 51:48, 1973.

8- Webster JP: Mastectomy for gynecomastia through semicircular intra-areolar incisions. Ann Surg 1946 ,557"124.

9- Wray RC, Hoopes JE, Davis GM: Correction of extreme gynecomastia. Br J Plast Surg 27"39, 1974.

10- Andrew N. Kornstein, M.D. and Peter B. Cinelli, (1992): Inferior Pedicle Reduction Technique for Larger Form of Gynecomastia , Aesth . Plast . Surg. 16:331-336, 1992.

11- Yavuz, M., Kesiktas, E., Kesiktas, N.N. and Acartürk, S. (2006) Lighted Retractor-Assisted Transaxillary Approach in Gynecomastia Correction. Annals of Plastic Surgery, 57, 370373.

12- Bembo, S.A. and Carlson, H.E. (2004) Gynecomastia: Its Features, and When and How to Treat It. Cleveland Clinic Journal of Medicine, 71, 511-517.

13- Simon BE, Hoffman S, Kahn S. Classification and surgical correction of gynecomastia. Plast Reconstr Surg. 1973;51:48-52.

14- Kasielska A, Antoszewski B (2013) Surgical management of gynecomastia: an outcome analysis. Ann Plast Surg 71(5):471-475.

15-Ismail Jatoi, Manfred Kaufmann, Jean Y. Petit (2006): Surgical Management of Gynecomastia, Atlas of Breast Surgery, Editor: Gabriele Schr der,Heidelberg, Germany. p 50.2006.

16- Fischer S, Hirsch T, Hirche C, Kiefer J, Kueckelhaus M, Germann G, Reichenberger MA. Surgical treatment of primary gynecomastia in children and adolescents. Pediatr Surg Int 2014;30:641-7. 
Int. J. Curr. Res. Med. Sci. (2017). 3(6): 176-182

\begin{tabular}{|c|c|}
\hline \multicolumn{2}{|c|}{ Access this Article in Online } \\
\hline \multirow{2}{*}{ 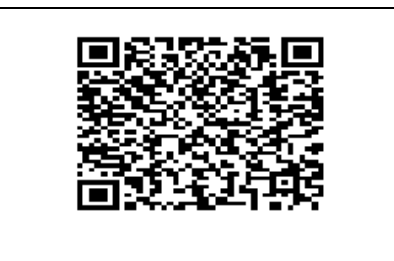 } & $\begin{array}{l}\text { Website: } \\
\text { www.ijcrims.com }\end{array}$ \\
\hline & \multirow[t]{2}{*}{$\begin{array}{l}\text { Subject: } \\
\text { Medical Sciences }\end{array}$} \\
\hline Quick Response Code & \\
\hline
\end{tabular}

How to cite this article:

Mostafa Mahmoud Salama, Mohammed Mamdouh Ahmed. (2017). Inferior Pedicle Reduction Technique With Nipple Repositioning for Huge Gynecomastia. Int. J. Curr. Res. Med. Sci. 3(6): 176182.

DOI: http://dx.doi.org/10.22192/ijcrms.2017.03.06.023 